\title{
Utilization of Preservative Technology in an Inventory System with Non-Instantaneous Deteriorating Goods
}

\author{
Subhankar Adhikari
}

\begin{abstract}
This work proposes a mathematical model based on the inventory of non-instantaneous deteriorating items. Effects associated with the investment in preservation technology have been considered in the proposed model. The objective of the aforesaid model is to determine optimal profit concerning two decisions variables. They are the length of the inventory cycle and the amount of investment regarding preservation technology. A numerical example has been exhibited in the support of this model. Maximization of profit function has been ensured numerically as well as graphically. A possible future extension of this model has also been indicated.
\end{abstract}

Keywords: Inventory, non-instantaneous deterioration, preservation technology, profit maximization.

\section{INTRODUCTION}

Deterioration is a common incident which associates with the inventories of different items. Volatile liquids, chemical products, agricultural products, food, and vegetables are the worst victim of deterioration. It should be noted that many of them do not deteriorate immediately with the commencement of the inventory cycle. In reality, deterioration starts after a time lag. As a consequence of deterioration, some amount of product is lost. Deterioration also hampers the quality of items. The strategy which reduces the intensity of the incident "deterioration" is always welcome in the business world. The corresponding strategy is usually named a preservation strategy. If some investment is made in the preservation strategy then it will incur some extra cost, but at the same time, the rate of deterioration may be reduced which is very fruitful for the market manager. Based on this conception, a mathematical model has been formulated.

\section{LITERATURE SURVEY}

Ghare and Schrader [1] were the pioneers to introduce incident deterioration in mathematical modeling. In that model, the inventory deteriorated at an exponential rate. Covert and Philip [2] considered the Weibull distribution for the time to deteriorate of inventory of items. Wee [3] formulated a model for perishable items with a price-sensitive demand pattern. Partial backlogging of shortages was also considered there. Extensive reviews on deteriorating items were conducted by Goyal and Giri [4].

Manuscript revised November 30, 2021 and published on December 10, 2021

Subhankar Adhikari, Department of Mathematics, Chandernagore College, Chandernagore, Hooghly, West Bengal, India.

Email: subhankar_adhikari@yahoo.com
Ouyang et al. [5] developed an illustration that involves non-instantaneous deteriorating items under the trade-credit policy. They further developed another work [6] which includes shortage as well as variable back-ordering rates. A linear form of stock-dependent demand pattern was considered by $\mathrm{Wu}$ et.al [7]. They incorporated a price-sensitive demand pattern in another work [8]. An inventory model for non-instantaneous items under permissible delay in payment atmosphere was developed by Geetha and Uthayakumar [9]. A time-dependent deterioration rate was assumed by Dye and Heish [10]. Then Dye [11] improved that model by taking non-instantaneous deteriorating items. Pricing policy for seasonal deteriorating items with the investment in the preservation technology was incorporated in the model formulated by He and Huang [12]. Both stock and price-sensitive demand pattern was considered by Soni [13]. In that model, there was also the concept of delayed payment. Zhang [14] incorporated a dynamic pricing strategy for non-instantaneous deteriorating items along with an inventory level-dependent demand rate. Jaggi et al. [15] formulate an inventory model for non-instantaneous deteriorating items with two-storage facilities. Bardhan et al. [16] proposed a non-linear stock-dependent demand pattern for non-instantaneous deteriorating items.

\section{BASIC ASSUMPTIONS WITH NOTATIONS}

- A single item is considered

- The time horizon is infinite

- The rate of demand $D$ is constant

- Deterioration starts after a period $t_{d}$ of commencement of the inventory cycle. The deterioration rate is constant

- The length of the inventory cycle is $T$. Two situations may arise according to as following conditions: $t_{d}<T$ or $t_{d} \geq T$

- $t_{d}$ is known from previous data

- Purchase cost is $c_{p}$ per unit item

- $\quad$ The selling price is $s$ per unit item

- $\quad c_{h}$ represents holding cost per unit item

- The total deteriorated item is represented by $Q_{d}$

- Set up cost is $k$ for each setup arrangement

- $\xi$ be the investment in preservation technology per unit time.

- $\quad$ Deterioration is reduced by the proposition $m(\xi)$ as a result of using preservation technology.

- Here $m(\xi)=1-e^{-a \xi}$ where $a>0$. This form is the same as Bardhan et al. [16]. 
- When $t_{d}<T, I_{1}(t)$ represent inventory level at time $t \in\left[0, t_{d}\right]$ and $I_{2}(t)$ when $t \in\left[t_{d}, T\right]$

- When $t_{d} \geq T, I_{3}(t)$ represents inventory level at time $t \in[0, T]$

- $\pi_{1}$ and $\pi_{2}$ are profit functions associated with situations $t_{d}<T$ or $t_{d} \geq T$ respectively

- $m$ and $m(\xi)$ will be used intercept ably throughout the paper.

\section{MODEL FORMULATION}

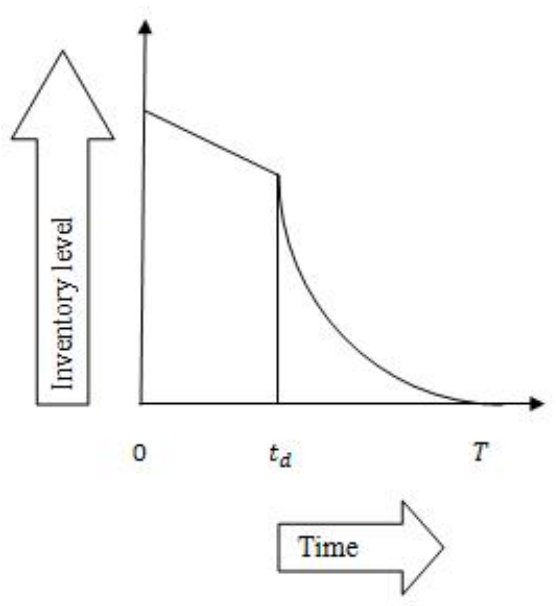

Figure 1: Time weighted inventory when $0<t_{d}<T$

This figure represents the depletion of inventory level with the progression of time when $t_{d}<T$. The event deterioration starts at the time $t=t_{d}$. There is no deterioration in the time interval $\left[0, t_{d}\right]$.

The differential equation which governs the inventory level for the time interval $\left[0, t_{d}\right]$ is described in the following manner

$\frac{d I_{1}}{d t}=-D$ with $I_{1}(0)=Q$

The solution of the above differential equation is given by

$I_{1}(t)=Q-D t$

Holding cost related to the interval $\left[0, t_{d}\right]$ is expressed as

$c_{h} \int_{0}^{t_{d}} I_{1}(t) d t$

$=c_{h}\left[Q t_{d}-\frac{D}{2} t_{d}^{2}\right]$

Now we will discuss the situation for the interval $\left[t_{d}, T\right]$

The corresponding equation handling the inventory level at any time $t \in\left[t_{d}, T\right]$ is described by

$\frac{d I_{2}}{d t}=-D-(1-m) \theta I_{2}$

Subject to $I_{2}(T)=0$

The solution of the aforesaid differential equation is

$I_{2}(t)=\frac{D}{(1-m) \theta}\left[e^{(1-m) \theta(T-t)}-1\right]$

As $Q_{d}$ represents items spoiled due to deterioration for the interval $\left[t_{d}, T\right]$, we try to find expression for it.

$Q_{d}=(1-m) \theta \int_{t_{d}}^{T} I_{2}(t) d t$
$=\frac{D}{(1-m) \theta}\left[e^{(1-m) \theta\left(T-t_{d}\right)}-1\right]-D\left(T-t_{d}\right)$

The total number of items are sold throughout the inventory cycle is $D T$. So the relation between total item $(Q)$ and deteriorated items $\left(Q_{d}\right)$ is given by

$Q-Q_{d}=D T$

Holding cost for the interval $\left[t_{d}, T\right]$

$=c_{h} \int_{t_{d}}^{T} I_{2}(t) d t$

$=\frac{D}{(1-m)^{2}(\theta)^{2}}\left[e^{(1-m) \theta\left(T-t_{d}\right)}-1\right]-\frac{D}{(1-m) \theta}\left(T-t_{d}\right)$

Total Profit

$=[$ Sales revenue - ordering cost - holding cost - preservation investment-oriented cost - purchase cost]

$\pi_{1}=$ Average total profit $=\frac{1}{T}($ Total Profit $)$

$\pi_{1}=\frac{1}{T}\left[\begin{array}{c}s\left(Q-Q_{d}\right)-k-c_{h} \int_{0}^{t_{d}} I_{1}(t) d t- \\ c_{h} \int_{t_{d}}^{T} I_{2}(t) d t-T \xi-c_{p} Q\end{array}\right]$

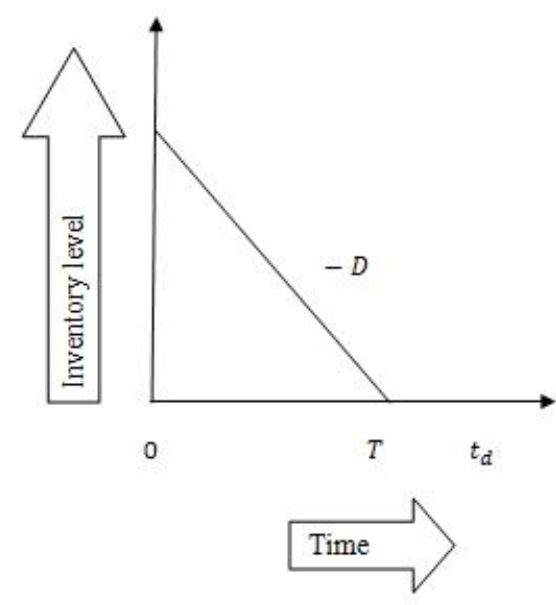

Figure 2: Time-weighted inventory when $t_{d}>T$

This diagram reflects the inventory level when the cycle of inventory ends before the commencement of deterioration. In this situation, deterioration does not affect reducing the inventory level.

The differential equation associated with the inventory level is written as

$\frac{d I_{3}}{d t}=-D$ with $I(T)=0$

This gives inventory level at any time $t \in[0, T]$

$I_{3}(t)=D(T-t)$

Holding cost for the period $[0, T]$ is calculated as

$c_{h} \int_{0}^{T} I_{3}(t) d t$

$=\frac{c_{h}}{2} D T^{2}$

[Using (11)]

Now average total profit in this case,

$\pi_{2}=\frac{1}{T} \quad$ [Sales revenue - set up cost - holding cost $]$

$\pi_{2}=\frac{1}{T}\left[\left(s-c_{p}\right) D T-k-\frac{c_{h}}{2} D T^{2}\right]$

The average total profit function for this model is defined as $\pi=\left\{\begin{array}{l}\pi_{1} \text { for } t_{d}<T \\ \pi_{2} \text { for } t_{d} \geq T\end{array}\right.$

$\pi$ is a continuous function at time $T=t_{d}$ 


\section{Solution Procedure}

Two cases will be dealt with separately.

When $t_{d}<T$, we first find the necessary condition of maximization of a function.

$\frac{\partial \pi_{1}}{\partial T}=0, \frac{\partial \pi_{1}}{\partial \xi}=0$ gives the length of the cycle and investment amount per cycle.

The solutions obtained are optimal if the eigenvalues of the following Hessian matrix $(H)$ are negative.

$H=\left(\begin{array}{cc}\frac{\partial^{2} \pi_{1}}{\partial T^{2}} & \frac{\partial^{2} \pi_{1}}{\partial T \partial \xi} \\ \frac{\partial^{2} \pi_{1}}{\partial T \partial \xi} & \frac{\partial^{2} \pi_{1}}{\partial \xi^{2}}\end{array}\right)$

In this case, the profit function is highly non-linear. The numerical solution is possible instead of analytical solutions. For obtaining a numerical solution, the help of the Software MATHEMATICA is taken.

When $t_{d} \geq T$, profit function is in an easier form. So in this case we deal with analytical solutions.

The necessary condition is $\frac{d \pi_{2}}{d T}=0$

Now,

$\frac{d \pi_{2}}{d T}=\frac{k}{T^{2}}-\frac{c_{h} D}{2}$

Using necessary conditions, the cycle length associated with inventory is obtained as

$T=\sqrt{\frac{2 k}{D c_{h}}}$

The sufficient condition gives,

$\frac{d^{2} \pi_{2}}{d T^{2}}=-2 \frac{k}{T^{3}}$

Since both $k$ and $T$ are positive, we have

$\frac{d^{2} \pi_{2}}{d T^{2}}<0$. This confirms that the profit function $\pi_{2}$ is maximized.

\section{NUMERICAL ILLUSTRATION}

To validate this model the following numerical example is considered.

\begin{tabular}{|l|l|}
\hline Parameter & Values \\
\hline Demand rate $(D)$ & 5000 units \\
\hline Deterioration rate $(\theta)$ & 0.3 \\
\hline Selling price $(s)$ & $\$ 35$ per unit \\
\hline Purchase cost $\left(c_{p}\right)$ & $\$ 20$ per unit \\
\hline Set up cost $(k)$ & $\$ 1200$ per setup \\
\hline Holding cost $\left(c_{h}\right)$ & $\$ 5$ per unit \\
\hline $\begin{array}{l}\text { The index associated with an } \\
\text { investment in preservation } \\
\text { technology }(a)\end{array}$ & 0.01 \\
\hline $\begin{array}{l}\text { Deterioration starting } \\
\text { moment }\left(t_{d}\right)\end{array}$ & 0.0417 year \\
\hline
\end{tabular}

Applying those values of the parameter in this model we get the optimal results

\begin{tabular}{|l|l|}
\hline Decision variables & Optimal results \\
\hline Cycle length $\left(T^{*}\right)$ & 0.304 year \\
\hline Investment in preservation & $\$ 356.04$ \\
\hline
\end{tabular}

\begin{tabular}{|l|l|}
\hline technology per unit time $(\xi)$ & \\
\hline Average total profit $\left(\pi_{1}\right)$ & $\$ 66796.90$ \\
\hline
\end{tabular}

These results are optimal since the Eigenvalues of the Hessian matrix

$H=\left(\begin{array}{cc}\frac{\partial^{2} \pi_{1}}{\partial T^{2}} & \frac{\partial^{2} \pi_{1}}{\partial T \partial \xi} \\ \frac{\partial^{2} \pi_{1}}{\partial T \partial \xi} & \frac{\partial^{2} \pi_{1}}{\partial \xi^{2}}\end{array}\right)$

are all negative and their values are given by $-85117.3,-0.00978614$.

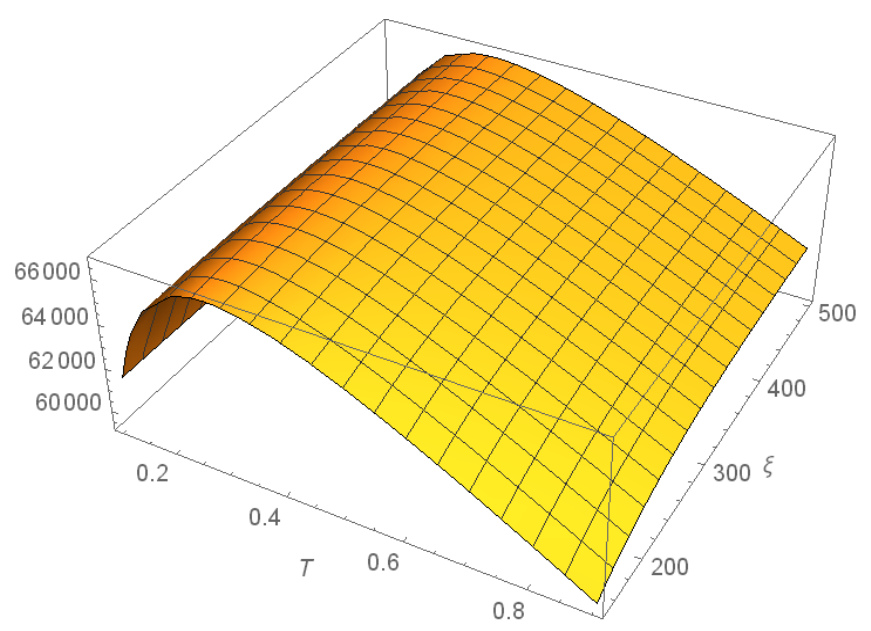

Figure 3: Three-dimensional representation of profit function with respect to decision variables when there is an investment in preservation technology

If there is no investment in the preservation of technology $(\xi=0)$, we get the following result

\begin{tabular}{|l|l|}
\hline Decision variables & Optimal results \\
\hline Cycle length $\left(T^{*}\right)$ & $0.2075 y e a r$ \\
\hline $\begin{array}{l}\text { Average total profit } \\
\left(\pi_{2}\right)\end{array}$ & $\$ 64553.70$ \\
\hline
\end{tabular}

Clearly, profit is more when the investment in preservation technology is made.

\section{CONCLUSION}

In this work, the effect of applying investment in preservation technology for non-instantaneous items has been examined. The optimal cycle length of the inventory and investment in the field of preservation technology has been obtained based on a profit maximization strategy. Results are shown for both of the situations associated with investment or non-investment regarding preservation strategy. As deterioration spoils goods very badly, this technique may be 
an effective tool for the sellers of different kinds of perishable goods.

\section{FUtURE DIRECTIONS OF RESEARCH}

In this work, we have assumed the deterioration commencement moment as a known thing. If this moment is not known, then an interesting extension can be made on basis of that fact. Shortages may be allowed and different types of backlogging can be done as an extension of this work.

\section{REFERENCES}

[1] Ghare, P.M, Schrader, G.H, (1963), “A model for exponentially decaying inventory", Journal of Industrial Engineering, vol. 14, No.5, pp. 238-243.

[2] Covert, R.P, Philip, G.C., (1973), “An EOQ model for items with weibull distribution deterioration", American Institute of Industrial Engineering Transactions, vol.5, no.4, pp. 323-326.

[3] Wee, H.M, (1999), "Deteriorating inventory model with a quantity discount, pricing and partial backlogging", International Journal of Production Economics, vol.59, no.1-3, pp.511-518.

[4] Goyal, S.K, Giri, B.C, (2001), "Recent trend in modeling of deteriorating inventory", European Journal of Operational Research, vol.134, pp.1-16.

[5] Ouyang, L.Y, Wu, K.S, Yang, C.T, (2006), “A study on an inventory model for non-instantaneous deteriorating items with permissible delay in payments", Computers and Industrial Engineering, vol.51, no.4, pp.637-651.

[6] Ouyang, L.Y, Wu, K.S, Yang, C.T, (2008), “ Retailers ordering policy for non-instantaneous deteriorating items with a quantity discount, stock dependent demand and stochastic backorder rate", Journal of Chinese Institute of Industrial Engineers, vol.25, no.1, pp.62-72.

[7] Wu, K.S, Ouyang, L.Y, Yang, C.T, (2006), “An optimal replenishment policy for non-instantaneous deteriorating items with stock dependent demand and partial backlogging", International Journal of Production Economics, vol.101, pp.369-386.

[8] Wu, K.S, Ouyang, L.Y, Yang, C.T, (2009)," Coordinating replenishment and pricing policies for non-instantaneous deteriorating items with price-sensitive demand", International Journal of System Science, vol.40, no.12, pp.1273-1281.

[9] Geetha, K.V, Uthayakumar, R, (2010), "Economic design of an inventory policy for non-instantaneous deteriorating items under permissible delay in payments", Journal of Computational and Applied Mathematics", vol.233, pp.2492-2505.

[10] Dye, C.Y, Heish, T.P, (2012), "An optimal replenishment policy for deteriorating items with effective investment in preservation technology", European Journal of Operational Research, vol.218, pp.106-112.

[11] Dye, C.Y, (2013), “The effect of preservation technology investment on a non-instantaneous deteriorating inventory model", Omega, vol.41, pp.872-880.

[12] He, Y., Huang, H., (2013), “ Optimizing inventory and pricing policy for seasonal deteriorating products with preservation technology", Journal of Industrial Engineering, article ID 793568.

[13] Soni, H.N, (2013), "Optimal replenishment policies for non-instantaneous deteriorating items with price and stock sensitive demand under permissible delay in payments", International Journal of Production Economics, vol.146, pp.259-268.

[14] Zhang, J., Wang, Y., Lu, L., Tang, W, (2015), “Optimal dynamic pricing and replenishment cycle for non-instantaneous deteriorating items with inventory level dependent demand", International Journal of Production Economics, vol.170, pp.136-145.

[15] Jaggi, C.K, Tiwari, S., Goel, S.K, (2016), “ Credit financing in economic ordering policies for non-instantaneous deteriorating items with price dependent demand and two storage facilities", Annals of Operations Research, vol.248, no.1, pp. 253-280.

[16] Bardhan, S., Pal, H., Giri, B.C., (2019)," Optimal replenishment policy and preservation technology investment for a non-instantaneous deteriorating item with stock-dependent demand, Operational Research, vol.19, no.2, pp.347-368.

\section{Author ProfiLe}

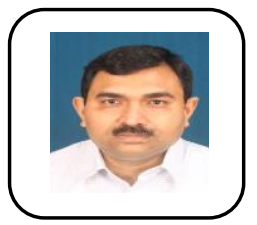

SUBHANKAR ADHIKARI is an Assistant Professor in Mathematics at CHANDERNAGORE COLLEGE. He has obtained an M.SC degree in Mathematics from Jadavpur University, Kolkata. $\mathrm{He}$ has published papers in the International Journal of System Science: Operations and Logistics, RAIRO-Operations Research, and the International Journal of Mathematics in Operational Research. His research area includes an inventory system and supply chain management. 